Initial presentation of childhood-onset systemic lupus erythematosus: a French multicenter study. The Journal of Pediatrics, 146(5):648-53.

[6] Singh S, Gupta MK, Ahluwalia J, Singh P, Malhi P (2009): Neuropsychiatric manifestations and antiphospholipid antibodies in pediatric onset lupus: 14 years of experience from a tertiary center of North India. Rheumatology International, 29(12):1455-61

Disclosure of Interests: None declared

DOI: 10.1136/annrheumdis-2019-eular.559

\section{AB0979 CORTICOSTEROID TREATMENT IN PEDIATRIC RHEUMATIC DISEASES AND SUPPRESSION OF THE HYPOTHALAMIC-PITUITARY AXIS}

Teresa Giani ${ }^{1}, 2$, Francesca Falorni ${ }^{1}$, Rolando Cimaz ${ }^{3} .{ }^{1}$ Pediatric Rheumatology, Meyer Children's University Hospital of Florence, Florence, Italy, ${ }^{2}$ Department of Medical Biotechnology University of Siena, Siena, Italy; ${ }^{3}$ Pediatric Rheumatology, Meyer Children's University Hospital of Florence, Florence, Italy

Background: Corticosteroids are the mainstay in the treatment of several chronic inflammatory diseases. Long-term treatment may lead to suppression of hypothalamic-pituitary-adrenal axis, which in turn can be dangerous in stress situations such as after surgical interventions. Oral replacement therapy may be needed in some cases. Data on pediatric populations are scanty.

Objectives: The aim of our study has been to evaluate hypothalamicpituitary-adrenal function during corticosteroid tapering by measuring serum cortisol.

Methods: During long term corticosteroid treatment, serum cortisol levels were evaluated when oral prednisone dose was decreased to $7.5 \mathrm{mg} /$ day and also after 4-6 weeks, and if below range ACTH levels were also determined.

All patients aged $<18$ years seen in our center during the last 6 months who were on corticosteroid treatment for $>1$ month were included. Serum cortisol levels were considered normal if in the range of 5-25 $\mu \mathrm{g} / \mathrm{dL}$ in a morning fasting blood drawing, while ACTH levels were considered normal in between 6 and $55 \mathrm{ng} / \mathrm{L}$ (with chemiluminescent method). Clinical and demographic data were recorded from clinical charts in a customized database.

Results: We have included in this preliminary study 12 patients $(7 \mathrm{~F}, 5 \mathrm{M})$ affected by uveitis $(n=4)$, JIA $(n=4)$, scleroderma $(n=3)$, lupus $(n=1)$. The mean age (at the time of sampling) was 11.5 years, with a median of 10 and a range of $8-17$. Prednisone starting dose was $1 \mathrm{mg} / \mathrm{kg} /$ day.

Four out of 12 patients had decreased cortisol levels. Characteristics of these four patients (none of whom had additional steroid pulses) are detailed in the table.

Conclusion: One third of our patients had decreased cortisol levels, after three months of prednisone treatment. In one case, who showed persistent low levels, oral supplementation with hydrocortisone $20 \mathrm{mg} /$ day for two months was needed. Our study is ongoing and results could help in identifying patients at risk for adrenal crisis.

\section{REFERENCES}

[1] Gangadharan A, McCoy P, Phyo A, McGuigan MP, Dharmaraj P, Ramakrishnan R, McNamara PS, Blair J, "Recovery of hypothalamo-pituitaryadrenal axis suppression during treatment with inhaled corticosteroids for childhood asthma", J Asthma Allergy. 2017 Dec 15;

[2] Sidoroff M, Kolho KL, "Screening for adrenal suppression in children with inflammatory bowel disease discontinuing glucocorticoid therapy", BMC Gastroenterol. 2014 Mar 24;

[3] Ahmet A, Brienza V, Tran A, Lemieux J, Aglipay M, Barrowman N, Duffy C, Roth J, Jurencak R, "Frequency and Duration of Adrenal Suppression Following Glucocorticoid Therapy in ChildrenWith Rheumatic Diseases"; Arthritis Care Res (Hoboken). 2017 Aug;

Disclosure of Interests: None declared DOI: 10.1136/annrheumdis-2019-eular.2744

\section{AB0980 \\ EFFICACY OF ETANERCEPT TREATMENT FOR CHILDREN WITH KAWASAKI DISEASE INTRACTABLE TO INTRAVENOUS IMMUNOGLOBULIN THERAPY IN RUSSIAN CHILDREN}

Anastasiya Glazyrina ${ }^{1,2}$, Seda Kurbanova $a^{1,2}$, Marina Kantemirova $^{1,2}$

Yuliya Novikova ${ }^{1,2}$, Dmitry Ovsyannikov ${ }^{1,2}$, Elena Zholobova ${ }^{1}$, Saniya Valieva ${ }^{1}$,

Elena Petryaykina ${ }^{1}{ }^{1}$ Morozovskaya children's city clinical hospital, Moscow,

Russian Federation; ${ }^{2} R U D N$-University, Moscow, Russian Federation

Background: Kawasaki disease (KD) is recognized in developed countries as a fundamental reason of acquired heart diseases in children nowadays. The main treatment is infusion of intravenous immunoglobulin (IVIG) at a dose of $2 \mathrm{~g} / \mathrm{kg}$. However for about $10-30 \%$ of children is reported the development of resistance to standard therapy: continuance of fever $\left(\geq 38,0{ }^{\circ} \mathrm{C}\right)$ or recurrency of fever after 36 hours afebrile period $(T<37,5$ ${ }^{\circ} \mathrm{C}$ ), but not later than on the 7th day after completion of the IVIG infusion at a dose of $2 \mathrm{~g} / \mathrm{kg}$. Until now there are no unified recommendations for treatment of such patients. As alternative therapy researchers empirically apply second infusion of IVIG $(77 \%)$, high doses of glucocorticoids $(18 \%)$, blockers of tumor necrosis factor $\alpha(3 \%)$ and interleukin-1, cyclosporine and other cytostatic drugs.

Objectives: Efficacy evaluation of therapy by inhibitor of TNF-alpha (Etanercept) in treatment of KD immunoglobulin -resistant forms according to the data from Morozovskaya Children's City Clinical Hospital,Moscow.

Methods: There were examined 152 patients (boys:girls - 2:1, median age $\mathrm{Me}=21$ months $[10 ; 36]$ ) with $\mathrm{KD}$ hospitalized in Morozovskaya Children's City Clinical Hospital in 2014-2018. The frequency of complete form of KD was $80,6 \%$. All children had a standard therapy -IVIG. Efficacy evaluation was based on normalization of body temperature, decrease of neutrocytosis, decrease of C-reactive protein (CRP) level. In case of ineffectiveness of therapy the second infusion of IVIG, pulse-therapy and inhibitor of TNF-alpha (Etanercept) were used

Results: The resistance to standard IVIG therapy was revealed in 16 children $(10,5 \%)$, mostly in boys $(4,3: 1)$ at the age of $\mathrm{Me}=21,5$ months [9,5; 34]. Complete form of KD was diagnosed in 11 patients $(68,8 \%)$, incomplete form - in 5 children $(31,2 \%)$. Cardiovascular lesions were noted in 14 children (87,5\%): pericarditis - in $2(12,2 \%)$, coronary arteries (CA) lesions - in $12(75 \%)$, with formation of aneurysms in $8(50 \%)$, including the giant ones in 3 children (18,8\%); peripheral arteries damages were noted in 2 children (12,5\%), thrombosis and thromboembolism - in 4 children (25\%).

To all of children was made the second IVIG infusion, 13 of those children $(81,2 \%)$ had a positive effect:11 children with complete form of $K D$, 2 children with incomplete form of KD. For 3 children (18,7\%) with incomplete form of KD and significant cardiovascular changes (pericarditis, giant aneurysm of coronary and peripheral arteries,thrombosis and thromboembolism) it was needed an additional therapy. As a second-line therapy the methylprednisolone pulse-therapy was used in 2 children(12,5\%) at a dose of $10 \mathrm{mg} / \mathrm{kg}$, without sufficient effect. For these three patients (3) as a third-line therapy was applied Etanercept at a dose of $0,8 \mathrm{mg} /$ $\mathrm{kg} / \mathrm{a}$ week subcutaneousely. In all children normalization of body temperature, decrease of leukocytosis by factor of 1,5-3 and decrease of CRP by factor of 10-15 occurred after three injections of Etanercept. However, for 1 child it was needed the additional fourth injection of Etanercept because of repeated fever, increased laboratory parameters, development of thrombosis of the left coronary artery after 2 weeks upon discharge.

Conclusion: The frequency of immunoglobulin-resistant forms was 10, $5 \%$. The first-line therapy of resistance (second IVIG-infusion) was efficient in 13 children $(81,2 \%)$. Methylprednisolone pulse therapy was ineffective. The use of 3 subcutaneous injections of Etanercept at a dose of $0,8 \mathrm{mg} / \mathrm{kg} / \mathrm{a}$ week resulted in decrease of intensity of inflammatory changes and in fever relief, but it did not prevent the development of relapse and thrombosis of coronary arteries.

Disclosure of Interests: : Anastasiya Glazyrina: None declared, Seda Kurbanova: None declared, Marina Kantemirova: None declared, Yuliya Novikova: None declared, Dmitry Ovsyannikov: None declared, Elena Zholobova Grant/research support from: Roche, Pfizer, Novartis, Consultant for: Pfizer, AbbVie, Roche, BMS, Novartis, MSD, Speakers bureau:

\begin{tabular}{|c|c|c|c|c|c|c|c|c|}
\hline Patient & Gender & Age & Disease & $\begin{array}{c}\text { PDN initial } \\
\text { dose } \\
\text { [mg/Kg/die] }\end{array}$ & $\begin{array}{l}\text { PDN duration of therapy up to } 7.5 \mathrm{mg} / \\
\text { day }\end{array}$ & $\begin{array}{c}\text { Cortisolemia } \\
(1) \\
{[\mathrm{mcg} / \mathrm{dl}]}\end{array}$ & $\begin{array}{c}\text { Cortisolemia } \\
(2) \\
{[\mathrm{mcg} / \mathrm{dl}]}\end{array}$ & $\begin{array}{l}\text { ACTH } \\
{[\mathrm{ng} / \mathrm{L}]}\end{array}$ \\
\hline$\overline{1}$ & $M$ & 17 & Uveitis & 0.9 & 3 months & 4,37 & $\mathrm{~N} / \mathrm{A}$ & $\overline{N / A}$ \\
\hline 2 & $\mathrm{~F}$ & 13 & Scleroderma & 1 & 3 months & 2,87 & 5,22 & 15,90 \\
\hline 3 & $\mathrm{~F}$ & 8 & JIA & 1.4 & 4 months & 0.20 & 2.68 & 7.98 \\
\hline 4 & $\mathrm{M}$ & 10 & Uveitis & 1.3 & 3 months & 4.3 & $\mathrm{~N} / \mathrm{A}$ & 25.01 \\
\hline
\end{tabular}

